\section{Changes in plasma urate concentration immediately after acute myocardial infarction}

\author{
P GHOSH, A M G COCHRANE, P W N GORDON, \\ A G RADCLIFFE
}

British Medical fournal, 1975, 4, 261-262

\begin{abstract}
Summary
The plasma urate concentration of 70 patients with acute myocardial infarction increased progressively up to the seventh day and was significantly higher than in a group of 23 patients with ischaemic changes only. Diuretic treatment might have accounted for an early rise in urate levels but the persistent increase seen at seven days could not be so explained.
\end{abstract}

\section{Introduction}

As early as 1907 Futcher $^{1}$ mentioned coronary arteriosclerosis, angina pectoris, and fatty degeneration of the heart muscle as cardiovascular complications of gout. In 1951 Gertler et al ${ }^{2}$ showed that the incidence of hyperuricaemia in patients with myocardial infarction was higher than that in matched controls. Since then numerous reports have shown the association between hyperuricaemia and coronary artery disease. ${ }^{3}$ There are, however, no reports of the serial changes in urate concentration after acute myocardial infarction. We describe here these changes in patients admitted to the coronary care unit (CCU) at Addenbrooke's Hospital, Cambridge, over six months.

\section{Patients and methods}

One-hundred-and-nine patients admitted consecutively to the CCU were initially included in the study. Sixteen patients were later excluded because of death or a previous history of gout or because no initial urate value was obtainable. Seventy of these 93 patients had the serial electrocardiographic (ECG) changes of acute myocardial infarction or an aspartate aminotransferase (SGOT) level above $40 \mathrm{IU} / 1$ (acute myocardial infarction (AMI) group); the remaining 23 had ECG changes indicative of ischaemia and no increase in SGOT level (ischaemic group). All patients were observed for at least 24 hours in the CCU and serial 12-lead ECGs and enzyme estimations were carried out for at least three days after admission. Urate ${ }^{4}$ creatinine $^{5}$ and SGOT ${ }^{6}$ concentrations were also measured, after a 10 hour fast, on the 1st, 4th, 7th, and 14th days after admission. A coronary prognostic index $(\mathrm{CPI})^{7}$ was calculated for all the patients with $\mathrm{AMI}$ on the day of admission.

\section{Department of Medicine, University of Cambridge, Cambridge CB2 2QQ \\ P GHOSH, MRCP, research assistant}

Addenbrooke's Hospital, Cambridge CB2 2 QQ

A M G COCHRANE, MRCP, medical registrar (present address: King's College Hospital, London SE5)

P W N GORDON, MRCPATH, senior registrar

A G RADCLIFFE, MB, BS, house physician (now surgical registrar)

\section{Results}

The mean urate and creatinine concentrations in the AMI group were significantly higher $(P<0.005)$ than those in the ischaemic group on all the days tested (table I). In the AMI group the urate level was significantly higher on the 7 th $(P<0.005)$ and 14th day $(P<0.05)$ than on the first day. No such rise occurred in the ischaemic group. Creatinine levels remained stable in both groups. The highest urate concentration was significantly correlated with the CPI $(r=$ $0.302 ; P<0.01)$ but not with the highest SGOT level $(r=0.11$; $\mathrm{P}=\mathrm{NS}$ ).

TABLE I-Mean ( $\pm S E$ of mean) plasma urate and creatinine concentrations in 70 patients who suffered AMI and 2.3 who suffered ischaemic changes

\begin{tabular}{|c|c|c|c|c|}
\hline Day: & 1 & 4 & 7 & 14 \\
\hline $\begin{array}{l}\text { Urate (mmol/1): } \\
\text { AMI group } \\
\text { Ischaemic }\end{array}$ & $0 \cdot 347 \pm 0.010$ & $0.373 \pm 0.014^{*}$ & $0.380 \pm 0.012 \ddagger$ & $0.376 \pm 0.012 \S$ \\
\hline $\begin{array}{l}\text { group } \\
\text { Creatinine }\end{array}$ & $0.285 \pm 0.015$ & $0.274 \pm 0.014 \dagger$ & $0.275 \pm 0.012 \dagger$ & $0.277 \pm 0.018 \dagger$ \\
\hline AMI group & $105 \pm 2 \cdot 7$ & $110 \pm 2 \cdot 7$ & $104 \pm 2 \cdot 7$ & $110 \pm 2 \cdot 7$ \\
\hline group & $80 \pm 3 \cdot 5$ & $80 \pm 4 \cdot 4$ & $80 \pm 4 \cdot 4$ & $80 \pm 5 \cdot 3$ \\
\hline
\end{tabular}

Paired $t$ test between 1 st and 4th days, 1st and 7th days, and 1st and 14th days: $* \mathrm{P}<0 \cdot 1$.

$\dagger P \geqslant 0 \cdot 1$ (not significant)

$\underset{\mathrm{IP}}{\mathrm{tP}}<0.005$.

$\$ \mathrm{P}<0.05$.

Conversion: $S I$ to traditional units

Creatinine: $1 \mu \mathrm{mol} / 1 \approx 0.0113 \mathrm{mg} / 100 \mathrm{ml}$.

\section{Discussion}

These results show that urate concentrations increased until the seventh day in patients who had suffered AMI but not in those who suffered only ischaemic changes. The rise in urate concentration might have been due to either increased production or decreased excretion. Release of purines from damaged myocardial cells is unlikely to explain the increase in urate concentration as there was no correlation between the highest urate and SGOT levels, indicating that the extent and severity of myocardial necrosis did not parallel the rise in urate concentration. In addition, the maximum rise in SGOT occurred on the first day after admission whereas the increase in urate reached a peak on the seventh day. Although increased urate production from other sources could not be excluded a change in renal handling of urate after infarction is more likely to cause the increase. Failure of excretion of urate is a relatively common cause of hyperuricaemia. ${ }^{8}$ There was a significant correlation between the highest urate and highest creatinine concentrations in both the AMI $(r=0.42 ; P<0.001)$ and ischaemic $(r=0.65$; $P<0.001)$ groups. The higher creatinine concentration in the AMI group throughout the study suggests that renal factors may have played a major role in the hyperuricaemia. As diuretics inhibit secretion of urate in the distal tubules, resulting in hyperuricaemia, ${ }^{910}$ the results in the 70 patients with AMI were further analysed to investigate the effects of diuretics. The patients treated with diuretics had higher urate concentrations on the fourth day than those not receiving them (table II). Thus these drugs seem to have been responsible for an increase in urate levels, as there was no significant difference in urate concentrations between these two groups on the first day.

By the seventh day after admission, however, the urate concentration in patients with AMI not receiving diuretics had risen so that there was no longer a significant difference between these two groups. This suggests that other mechanisms, such as lactic acidaemia with raised acetoacetate and/or $\beta$-hydroxybutyr- 
TABLE II-Mean ( $\pm S E$ of mean) plasma urate concentrations (mmol/l) in patients who suffered $A M I$ according to whether they were given diuretics

\begin{tabular}{c|c|c|c|c}
\hline Day: & 1 & 4 & 7 & 14 \\
\cline { 2 - 5 } $\begin{array}{c}\text { Diuretics given } \\
(\mathrm{n}=38)\end{array}$ & $0.354 \pm 0.015$ & $0.409 \pm 0.021^{*}$ & $0.392 \pm 0.018$ & $0.382 \pm 0.016$ \\
$\begin{array}{c}\text { Diuretics not } \\
\text { given }(\mathrm{n}=32)\end{array}$ & $0.340 \pm 0.012$ & $0.327 \pm 0.015^{*}$ & $0.368 \pm 0.018$ & $0.368 \pm 0.018$ \\
\hline
\end{tabular}

$* \mathrm{P}<0.01$.

ate concentrations, may play a part in altering the renal handling of urate. These organic acids are thought to share a common secretory mechanism with urate and produce hyperuricaemia by competing with urate for this secretory site. ${ }^{11} 12$ Possibly also a more rapid turnover of preformed purines or increased de novo synthesis may have produced hyperuricaemia in the AMI group. Further study is in progress to elucidate the mechanism.

We thank the physicians of Addenbrooke's Hospital, Cambridge, for allowing us to study patients under their care and Professor $\mathrm{H}$ Lehmann for the laboratory facilities. P G was the holder of the Grimshaw-Parkinson Research Studentship at the University of
Cambridge and is at present receiving a grant from the Wellcome Trust. Requests for reprints should be addressed to P G, Department of Medicine, University of Cambridge, Addenbrooke's Hospital, Hills Road, Cambridge CB2 2QQ.

\section{References}

1 Futcher, T B, Modern Medicine, ed W Osler and T McCrae, 1st edn, vol I, p 108. Philadelphia and New York, Lea Bros, 1907.

${ }^{2}$ Gertler, M M, Garn, S M, and Levine, S A, Annals of Internal Medicine, $1951,34,1421$.

${ }^{3}$ Lancet, 1969, 1, 358.

4 Technicon Method File No 13a.

5 Close-Moll, M, and Lines, J G, fournal of Clinical Pathology, 1972, 25, 603.

${ }^{6}$ LKB 8600 Reaction Rate Analyser, Method File No M GOT/GPT-B.

7 Norris, R M, et al, Lancet, 1969, 1, 274.

${ }^{8}$ Kelley, W N, Grobner, W, and Holmes, E, Metabolism, 1973, 22, 939.

${ }^{9}$ Demartini, F E, et al, American fournal of Medicine, 1962, 32, 572.

${ }^{10}$ Laraugh, J H, et al, Annals of the New York Academy of Sciences, 1966, 139, 453.

$11 \mathrm{Yu}, \mathrm{T}-\mathrm{F}$, et al, Proceedings of the Society of Experimental Biology and Medicine, 1957, 96, 809.

12 Goldfinger, S, Klinenberg, J R, and Seemiller, J E, New England fournal of Medicine, 1965, 272, 351.

\section{SHORT REPORTS}

\section{Subclavian vein cannulation : a new complication}

Subclavian vein cannulation complicated by hydrothorax and clinically detectable ascites has not been described previously. We report such a case and outline a procedure to recognize cannulation of the pleural space.

\section{Case Report}

A woman aged 67 had a gastro-oesophagectomy for gastric carcinoma through an upper transverse abdominal incision and a separate right thoractomy; the defect was reconstructed with a Roux loop of jejunum. The early postoperative period was uneventful. As the peripheral veins became thrombosed the left subclavian vein was cannulated by the supraclavicular route for intravenous feeding. Blood was not aspirated after the cannula was advanced through the needle, but an $x$-ray film of the chest was taken following the

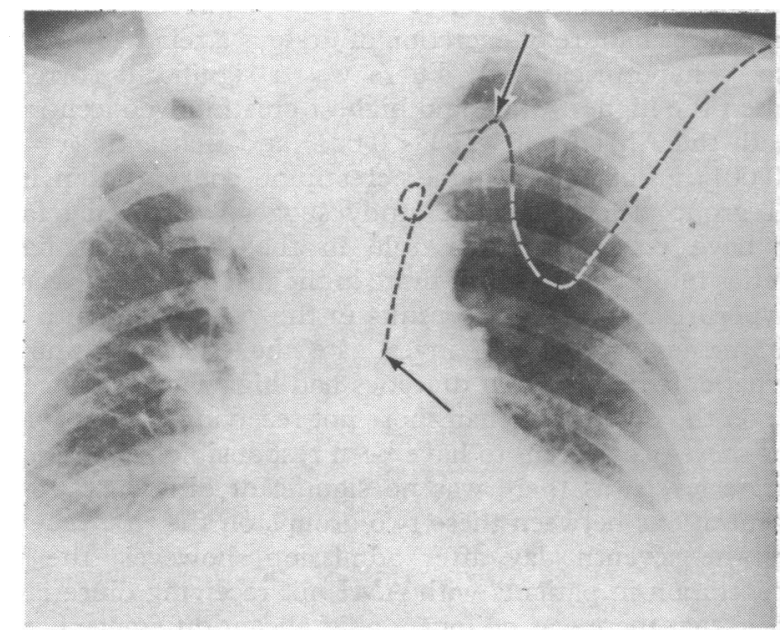

Semi-erect $x$-ray film of the chest immediately after insertion of cannula. Arrows mark points of skin puncture and tip of cannula. insertion (see fig.). The $x$-ray film was satisfactory and an infusion of Aminoplex 5 (containing amino-acids, sorbitol, ethanol, and electrolytes) was started at the rate of one litre every eight hours. After four days and 12 litres of Aminoplex the patient complained of dyspnoea and on examination had undoubted ascites and a left pleural effusion. An $x$-ray film of the chest confirmed this and the left chest was then aspirated and $1400 \mathrm{ml}$ of slightly blood-stained fluid obtained. The Aminoplex infusion was continued and by the next morning the patient was again extremely dyspnoeic. We saw the patient at this stage and confirmed the diagnosis of iatrogenic hydrothorax by aspirating clear fluid up the cannula in amounts far in excess of the cannula volume $(0.5 \mathrm{ml})$. After removal of the cannula the patient made an uneventful recovery with rapid and complete resolution of the effusion and ascites.

\section{Discussion}

Pneumothorax is a commonly reported complication of subclavian vein cannulation. Actual cannulation of the pleural space with the rapid development of a haemothorax or hydrothorax after infusing blood or clear fluid is reported less often.1-4 In this case an abnormal communication between the chest and abdominal cavities protected the patient against the immediate development of a significant hydrothorax. It was a failure to realize this point that led to a delay in diagnosis. Alternative causes of the effusion were sought, as clearly one could not put 12 litres of fluid into a chest. Cannulation of the pleural space in this patient should have been recognized at the time of insertion by the failure to aspirate blood after the cannula was advanced. Clearly, plain radiology will not differentiate between a cannula within the lumen of a vein and one advanced alongside. Similarly, a respiratory swing on a manometer does not exclude cannulation of the pleural space.

Cannulation of the pleural space, instead of the subclavian vein, can always be recognized by failure to aspirate blood on three occasions: on venepuncture, after the cannula has been advanced, and after a trial infusion of $100 \mathrm{ml}$ clear fluid.

This third test ensures that one has not been previously aspirating a large haematoma. The simplest way of making the third aspiration is to lower the whole infusion set below the patient and observe the line for reflux of blood. Such aspiration is also invaluable in suspected cases of late cannula displacement. This method is simpler than the injection of contrast medium down the cannula, as recently advocated by Shafig. ${ }^{5}$ The contrast injection technique, however, will show the precise anatomical location of any cannula, including those up which no fluid can be aspirated due to valvular mechanisms at the tip. 